\title{
A DIVERSIDADE NAS POLÍTICAS EDUCACIONAIS NO BRASIL
} DIVERSITY IN EDUCATIONAL POLICIES IN BRAZIL LA DIVERSIDAD EN LAS POLÍTICAS EDUCACIONALES EN BRASIL

\author{
Paulo Gomes Lima \\ Professor Doutor da Universidade Federal de São Carlos (UFSCar). \\ paulogl.lima@gmail.com
}

\begin{abstract}
RESUMO: O conceito e significado de diversidade nas políticas educacionais no Brasil e no mundo não deve deixar de considerar o contexto no qual tal tema é problematizado. $\mathrm{O}$ objetivo desse artigo, por meio de uma pesquisa exploratória, orientada por revisão bibliográfica e documental é discutir, não apenas a dimensão do conceito sobre diversidade existente nas políticas educacionais no Brasil, mas a recorrência da ampliação e alcance do mesmo nalgumas estratégias voltadas à sua efetivação como direito e respeito às singularidades. Nesse sentido, organizamos o presente trabalho em três seções: a) Diversidade nas políticas educacionais: do conceito aos seus significados; b) Diversidade nas políticas educacionais: do alcançado aos seus limites e c) Diversidade nas políticas educacionais: algumas pontuações e recorrências. Concluímos que as políticas educacionais universalizantes e para a diversidade solicitam a formação política do homem, objeto que não pode e não deve ser reduzida ao ideário particularizado de justiça social.
\end{abstract}

PALAVRAS-CHAVE: Diversidade. Políticas educacionais. Justiça social.

ABSTRACT: The concept and meaning of diversity in educational policies in Brazil and the world must not fail to consider the context in which such a theme is problematized. The objective of this article, through exploratory research guided by bibliographical and document review, is not only to discuss the dimension of diversity in educational policies in Brazil, but also the recurrence of its extension and scope in strategies aimed at its Effectiveness as a right and respect of singularities. In this sense, we organize this research into three sections: a) Diversity in educational policies: from concept to meanings; B) Diversity in educational policies: from reaching their limits and c) Diversity in educational policies: scores and recurrences. We conclude that universal educational policies and diversity demand political awareness of man, an object that cannot and should not be reduced to the particularized ideology of social justice.

KEYWORDS: Diversity. Educational policies. Social justice.

RESUMEN: El concepto y el significado de diversidad en las políticas educacionales en Brasil y en el mundo no pueden dejar de considerar el contexto en el que se problematiza ese tema. El objetivo de este artículo, a través de una investigación exploratoria, guiada por una revisión bibliográfica y documental, es discutir no sólo la dimensión del concepto de diversidad existente en las políticas educacionales en Brasil, sino también la repetición de su extensión y alcance en algunas estrategias dirigidas a su efectividad como derecho y respeto por las singularidades. En este sentido, organizamos el presente trabajo en tres secciones: a) Diversidad en las políticas educacionales: del concepto a sus significados; b) Diversidad en las políticas educacionales: del conquistado a sus límites y c) Diversidad en las políticas educacionales: algunas puntuaciones y recurrencias. Concluimos que las políticas educacionales universales y para la diversidad exigen la formación política del hombre, objeto que no puede ni debe reducirse a la ideología particularizada de la justicia social.

PALABRAS CLAVE: Diversidad. Políticas educacionales. Justicia social. 


\section{A DIVERSIDADE NAS POLÍTICAS EDUCACIONAIS NO BRASIL | Paulo Gomes Lima}

\section{1| INTRODUÇÃO}

Como política do Estado brasileiro a diversidade é destacada como objeto de recorrência no período de redemocratização, a partir dos anos de 1980, refletindo o espírito da Declaração dos Direitos Humanos de 1948, em relação à igualdade de reconhecimento quanto à ênfase da universalização de direitos, o que certamente fora um ponto muito significativo para a época, entretanto, ainda sem caracterizar um sentido convencionado tanto do conceito, quanto do alcance das políticas e suas respectivas estratégias de implementação.

Como observado em obra anterior seria necessário, não somente discutir, mas vivenciar e construir estratégias que ampliassem os significados de demandas sociais singulares que não mais poderiam estar à margem das solicitações sociais, mesmo porque o processo de abertura à redemocratização, trazia à tona a evocação de uma agenda de políticas não colocadas até então na ordem do dia da realidade brasileira. Logo se percebeu a partir da Constituição Federal de 1988 que somente a exigência do reconhecimento das desigualdades sociais, econômicas, culturais, não seria suficiente para a construção da igualdade, ou a igualdade de reconhecimento ao direito, por outro lado, esse primeiro olhar sobre a realidade no Brasil fora um importante indicador para se refletir a necessidade de mudanças numa sociedade antagônica como a capitalista. (LIMA, 2009).

A partir de Clements e Jones (2002, p.13), uma mesa redonda coordenada por Montagner et. al. (2010, p.21-22) destaca dois importantes entendimentos sobre diversidade ${ }^{1}$ que, em maior em menor grau, embora de origem internacional, muitas políticas de Estados-nação, passam a adotar, considerando as especificidades dos grupos humanos, seu movimento e produções. O primeiro enfatiza que a diversidade pode ser entendida, como ponto de partida, na observação e constatação de que os seres humanos são diferenciados e unidos por diferenças e semelhanças no âmbito de gênero, idade, idioma, cultura, raça, identidade sexual e nível de renda. O segundo entendimento identifica a diversidade com a alteridade, correspondendo às qualidades humanas distintas daquelas não familiares a um grupo humano ao qual se pertence, mas presentes e valoradas em outros grupos ou indivíduos. Portanto, não há um conceito único de diversidade, podendo inclusive ser definido como o enfrentamento de questões nas dimensões internas, externas e organizacionais das singularidades (ONU, 2000 apud CLEMENTS e JONES, 2002, p.13, In: MONTAGNER et.al, 2010, p.22) como se pode acompanhar na figura 1:

\footnotetext{
${ }^{1}$ A obra utilizada por Montagner et. al. (2010) para a apresentação dos entendimentos está em: CLEMENTS, Phillip Edward; JONES, John. The diversity training handbook: a practical guide to understanding and changing attitudes. $2^{\mathrm{a}}$ edição. Londres: Kogan Page, 2002.
} 
Figura 1 - Dimensões da diversidade

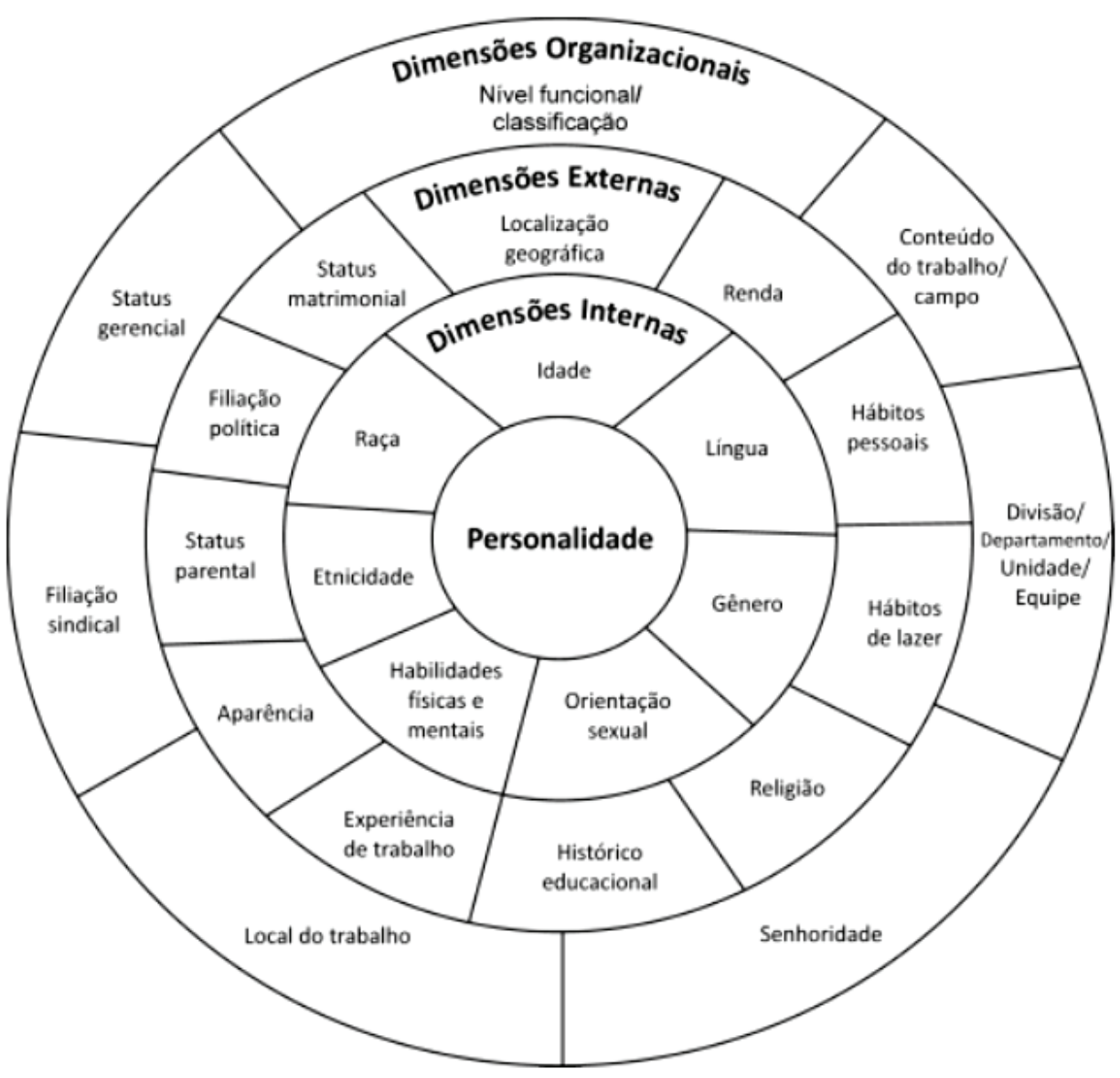

Fonte: Irwin (1995), apud London (2009) citado em Montagner et.al (2010, p.22).

O objetivo desse trabalho é discutir, não apenas a dimensão do conceito sobre diversidade existente nas políticas educacionais no Brasil, mas a recorrência da ampliação e alcance do mesmo nalgumas estratégias voltadas à sua efetivação como direito e respeito às singularidades. Nesse sentido, organizamos o presente trabalho em três seções: a) Diversidade nas políticas educacionais: do conceito aos seus significados; b) Diversidade nas políticas educacionais: do alcançado aos seus limites e c) Diversidade nas políticas educacionais: algumas pontuações e recorrências.

\section{2 | DIVERSIDADE NAS POLÍTICAS EDUCACIONAIS: DO CONCEITO AOS SEUS SIGNIFI- CADOS}

A discussão em torno da temática sobre o conceito e significado de diversidade nas políticas educacionais no Brasil e no mundo não deve deixar de considerar o contexto no qual tal tema é problematizado, ou seja, a partir de quais condicionantes socioeconômicos e políticos se desenvolvem os encaminhamentos para os conflitos existentes ou, para além do multicuralismo (sem deixar de o considerar) e do simples reconhecimento de oportunidades, isto é, na articulação entre lei e justiça, o que se busca para efetivação do direito de cidadania centrada em processos de não-exclusão. 


\section{A DIVERSIDADE NAS POLÍTICAS EDUCACIONAIS NO BRASIL | Paulo Gomes Lima}

Ora, na primeira perspectiva, as políticas educacionais voltadas para a diversidade se justificam pelo multiculturalismo, ou seja, as distintas origens devem ser observadas e o alunos incluído, tendo em vista a contenção ou melhoria das relações entre raças e, acrescento de características específicas de grupos humanos num contexto de "reparação" e inclusão social, numa ideia de compensação da supressão histórica de tais oportunidades. Nesse caso, a teoria do capital humano ${ }^{2}$, justifica as políticas de diversidade como a "necessidade de identificar talentos não aproveitados por deficiência do mercado (market failure)", o que resultará melhoria nas condições de vida e maior crescimento econômico para o país (SILVA, 2006, p.141).

Na segunda perspectiva, não se colocando à margem o contexto do conflito do mundo capitalista (compassado pelo neoliberalismo) pois é onde vivemos e de onde partimos, há uma busca e necessidade de construção de uma outra tipologia de quadro, em que a ideia de universalização não seja apenas uma previsão, mas um condicionante da não-excludência, uma vez que não reduz a cidadania a percentuais de oportunizações sociais, nem tampouco deixa de garantir as especificadades e direito à diferença. Algumas lutas tem sido enfrentadas nessa direção ${ }^{3}$ e ampliadas demandas (com todas as contenções socioeconômicas), contempladas ainda que não de forma universal, mas que primam pela superação do reducionismo capitalista nas políticas educacionais. A discussão sobre a diversidade nas políticas educacionais solicita a explicitação de seus conceitos e significados comumente aplicados e difundidos, quer em documentos oficiais, quer na literatura especializada.

As políticas educacionais são um recorte das políticas públicas, estas entendidas como caminho ou curso de ação preferido a outros pelas autoridades constituídas para o enfrentamento de questões ou problemas sociais. A sua efetivação é expressada em leis, regulamentos e normativas oficiais nas ações do governo; portanto, como observa Hofling trata-se do Estado em ação no atendimento ou provimento de demandas ou como afirma Hofling (2001, p.31), trata-se do Estado "[...] implantando um projeto de governo, através de programas, de ações voltadas para setores específicos da sociedade". Palumbo (1994) caracteriza as políticas públicas como "[...] um processo, ou uma série histórica de intenções, ações e comportamentos de muitos participantes"; nessa direção complementam Marran e Lima (2013), não se limitando, somente, a uma lei, pois sua construção se dá junto ao desenvolvimento dos fatos, num fluxo de construção, reconstrução e adaptação. Em sentido mais estrito, quanto à política pública, Palumbo vai defender que a "[...] sua manifestação visível é a estratégia adotada pelo governo para solucionar problemas públicos" (PALUMBO, 1994, p. 8), assim cada um dos problemas circunscritos a um corte estratégico de um país, como por exemplo, a educação, a saúde, a alimentação, o transporte, dentre outros setores poderiam ser caracterizadas como políticas públicas de corte social.

Como parte de uma política pública, a política educacional é pensada e estrutura em um ciclo que compreende: a agenda, a formulação, a implementação e a avaliação. A agenda se refere a

\footnotetext{
${ }^{2}$ Como observado em Lima (2009) a partir de Mészáros (2006, p.40): "A lógica do capital separa causas e efeito e apontam as soluções sociais corretivas como única forma possível de equidade, a exemplo do que afirmava Margaret Thatcher "não há alternativa" (There is not alternative) para a modificações do arranjo no mundo capitalista, por isso, justificava-se a "universalização de exceções", que na verdade atuava e atua como função ideológica da transformação em regra universal das condições rigorosamente excepcionais dos poucos privilegiados".

${ }^{3}$ Vale evocar aqui uma contribuição de Sanfelice (2006, p.39): "Caso queiramos pensar a inclusão educacional no Brasil, dentro de uma lógica libertadora e humanizadora, o desafio é bem maior. É preciso pensar esta sociedade como um todo e avaliar as condições históricas objetivas que nos disponibilizam, num trabalho coletivo, avançar em direção ao novo. Não um novo qualquer, mas um novo que supere qualitativamente o status quo de hoje. O problema não é legal e/ou formal. É um problema de fundo. Sem a superação da exploração do trabalho pelo capital, nada se transformará. Tudo se reproduzirá e as políticas inclusivas não perderão seu caráter sempre paliativo".
} 
identificação de demandas sociais advindas de distintos segmentos sociais e de múltiplos participantes. A formulação da política caracteriza-se pela composição do texto político, as contribuições de seus representantes internos e externos (os internos podemos dizer são os legisladores e externos, os consultores ou especialistas em áreas específicas, como por exemplo a do direito, antropologia, etc. A implementação corresponde ao momento de se colocar a política pensada por meio de programas, projetos e ações estratégicas organizadas para fazer frente às demandas identificadas na agenda. $E$ finalmente a avaliação, momento de analisar a validade ou não da política. Nesse sentido, pode ser avaliado a eficiência, eficácia e efetividade da política e os resultados e o alcance das políticas como devolutivas sociais.

Segundo Vidovich (2001), algumas questões que podem ser consideradas quando da formulação do texto da política são: a) Quando começou a construção do texto de política e 'porque agora' ou neste momento?; b) Quais grupos de interesse (partes interessadas) foram representados na produção do texto da política e quais foram os excluídos?; Quais processos foram usados para construir o texto de política e por quê?; d) Quais compromissos foram feitos entre os grupos de interesse diferentes (partes interessadas) e como eles foram alcançados? ; e) que interesses as políticas se propõem a cumprir?; f) Quais são os discursos dominantes do texto da política e os discursos que são excluídos?; g) Qual é a intenção ou propósito da política?; h) Na proposta da política elaborada, há agendas escondidas ou não explícitas?; i) Quais valores são refletidos na política?; j) Quais são as questões que constituem o foco da política, estas se referem a agendas de política global e internacional?; k) Quais são os principais conceitos ou conceitos-chave da política proposta?; I) Qual é o formato/tipologia de política adotado e por quê? m) Qual é a linguagem da política e por quê?; n) Há incoerências e contradições no texto política?; o) Quem é o público-alvo do texto política?; p) O texto da política é acessível ou compreensível para o público?; q) As etapas para 'implementação' são claramente definidas e integrantes do texto de política?; r) O processo de implementação terá recursos ou será financiado? s) Existe um mecanismo especificado para avaliar a política? Estas questões não esgotam as leituras possíveis do contexto da produção do texto da política, entretanto, constituem-se como elementos de reflexão que, em maior ou menor medida, poderão contribuir para melhor sua melhor compreensão.

No contexto da avalição da política, Vidovich (2001) propõe a s seguintes indagações ancoradas em saber "quais foram as forças ou efeitos que atuaram sobre o contexto da implementação prática da política? A essas seguem: a) Esta política está sendo implementada numa variedade de contextos?; b) Como se diferenciam as práticas de políticas para a realidade que foi desenhada ?; c) São evidentes as influências globais/internacionais no contexto da prática da política local ?; d) Quem pode ter acesso e quem efetivamente a acessa?; e) A interpretação da política é aberta e clara para os implementadores?; e) Como a política foi recebida pelos implementadores?; f) Quem colocou a política em prática e por quê?; g) Quais processos foram usados para colocar a política em prática e por quê?; h) Em que medida a política é resistida (ativa ou passivamente)?; i) A resistência é coletiva ou individual?; j) Em que medida a política é transformada em cada uma das instituições no processo de implementação? k) O processo de implementação das políticas, bem como os seus efeitos foram previstos?; I) Os implementadores das políticas fazem parte do contexto para o qual ela foi projetada?; $\mathrm{m}$ ) Os implementadores são capazes de responder e de se reunir prontamente para atender as necessidades localizadas no domínio do contexto da prática política?; n) Quais foram as consequências ou efeitos não intencionais no processo de implementação da política?; o) Qual é o impacto da política em diferentes agrupamentos localizados com base na classe, gênero, etnia, ruralidade e deficiência?; p) Existem vencedores ou perdedores no contexto da prática ou processo de implementação da política? 


\section{A DIVERSIDADE NAS POLÍTICAS EDUCACIONAIS NO BRASIL | Paulo Gomes Lima}

Ainda há que se lembrar que quanto a duas das tipologias de acesso as políticas públicas podem ser classificadas como universais ou focalizadas. A primeira tipologia corresponde a ao atendimento a todos indistintamente, considerando a cidadania como pressuposto de todos, assim também quando da apropriação dos direitos estabelecidos no Estado-nação. A segunda tipologia caracterizada pelo atendimento a grupos sociais, cuja vulnerabilidade social e histórica, não foram totalmente contemplados pelas políticas universais dadas as especificidades de seu contexto, identidade e condicionantes discriminatório e cujo direito à diferença não fora objeto de problematização e encaminhamento político e social. Como no caso das políticas de ações afirmativas, essa segunda tipologia é também tratada na literatura especializada como "discriminação positiva".

A diversidade, por sua vez, como temática e objeto das políticas educacionais não pode ser definida simplesmente como sinônimo do diverso, considerando os segmentos ou coletivos humanos ou ainda na conclusão de que o reconhecimento em si do multicultural resolve e harmoniza os conflitos situados historicamente. Presume sobretudo uma "[...] construção histórica, social, cultural e política das diferenças [...]" nesse sentido, os traços, identidade, relações, condicionantes e condicionamentos dos sujeitos sociais são distintos e transversalizados por complexas relações sociais de poder. Assim, a problematização sobre a necessidade da igualdade, as denúncias sobre as desigualdades sociais e o direito à diferença devem ser pauta e prática democrática de uma sociedade que procura romper com a perversidade e injustiça social (CONAE, 2014, p. 28). Nesse sentido como ponto inicial, o reconhecimento do direito à igualdade e a defesa da diferença são pontos necessários, mas solicita medidas que possam ampliar e serem difundidas como expressões do direito, fundamentadas na gestão democrática.

Portanto, o sentido e significado de colocar a diversidade como uma das agendas das políticas educacionais no Brasil, podem ser compreendidos como um enfrentamento dos contextos adversos aos quais, considerável parte da população historicamente é submetida. Nesse sentido, o empoderamento como construção e recorrência da diversidade na educação torna-se mola propulsora para um estágio de abertura e materialização de direitos, ampliando agendas e discutindo as relações entre os processos de democratização, humanização e universalização.

\section{3 | DIVERSIDADE NAS POLÍTICAS EDUCACIONAIS: DO ALCANÇADO AOS SEUS LIMITES}

De maneira ampla, a diversidade nas políticas educacionais aparece com forte necessidade de se enfatizar o respeito às diversidades culturais, às diferenças e singularidades dos grupos sociais, aos processos de inclusão social à educação de parte da população historicamente marginalizada por sua condição social, cor, raça, etnia, além de outros, as políticas de ações afirmativas, se caracterizam como exemplo. Entretanto, sabe-se que isso não significa que os movimentos que primam pela totalidade do atendimento aos direitos demandados, sejam atendidos. Ora, como destacado antes, a partir do documento da CONAE (2014), há uma complexa relação de poder permeada por grupos de pressão que maior ou menor medida inferem sobre a contenção e custos sociais, garantindo-se recorte delimitado dos benefícios sociais. Assim, embora algumas conquistas possam ser listadas, as tensões por sua ampliação permanecem recorrentes, como poderemos acompanhar a seguir.

\footnotetext{
${ }^{4}$ Em trabalho de pós-doutoramento Lima (2009, p.96) destaca que a: “[...] 'discriminação positiva' tem sido considerada como uma evolução cultural e humana que, finalmente o Brasil se deu conta na correção de sua dívida histórica, principalmente quanto à exclusão do negro das universidades e oportunidades sociais no mercado de trabalho, chegando-se a discussão da inclusão por gênero, grupos marginalizados e à classe economicamente desfavorecida".
} 


\section{A DIVERSIDADE NAS POLÍTICAS EDUCACIONAIS NO BRASIL | Paulo Gomes Lima}

Certamente o processo de redemocratização do Brasil, cuja expressão ampla trouxe em seu artigo 205 a educação como "[...] direito de todos e dever do Estado e da família..." em regime de colaboração entre os entes federados e expressão do exercício da cidadania. A categoria conceitual de cidadania do ponto de vista da justiça social, não poderia compactuar com o seu reducionismo ou interpretacionismo que se mostrasse conveniente com os processos de exclusão no âmbito do valor econômico, nem tampouco se contentar com o valor gnosiológico ou do conhecimento sobre o termo em nível de reconhecimento conceitual e seus limites, deveria ir além, ou seja, na concepção de cidadania enquanto valor ético-político. Nessa perspectiva, o reconhecimento do conceito e da expressão de seu alcance deveria ser acompanhado de medidas e estratégias de efetivação. Entretanto, essa construção embora com alguns insights governamentais ainda está em processo na realidade brasileira.

Conforme Rodrigues e Abramowicz (2013, p.25) o período de governo de Fernando Henrique Cardoso (1995-2002) correspondeu à consolidação de políticas focais de combate à discriminação, ao preconceito e ao racismo na esfera pública, entretanto, por seu caráter pontual não respondia ao que os movimentos sociais solicitavam, isto é, uma estratégia ordenada e de maior alcance, considerando sua complexidade. Etapas que seriam exigidas das posteriores gestões governamentais no Brasil. Assim, não se tratava de uma pauta simplesmente de iniciativa governamental, tratava-se de recorrências silenciadas e marginalizadas que eclodiam de forma mobilizada em distintos canais e setores sociais e que exigiam contrapartida.

No governo FHC, além da criação do Grupo de Trabalho Interministerial para a Valorização da População Negra $^{5}$ (BRASIL, 1996), identifica-se, dentre outras, as seguintes normativas e ações voltadas para a diversidade, embora naquele momento não houvesse qualquer definição formal ou discussão socialmente convencionada pelos educadores e legislação nacional:

\begin{tabular}{|c|c|c|}
\hline Ano & Indicador & Descritores \\
\hline 1996 & $\begin{array}{l}\text { Lei de Diretrizes e Bases da Educação } \\
\text { Nacional 9394/1996. }\end{array}$ & $\begin{array}{l}\text { Artigos de atendimento amplo às demandas de educação no Brasil, al- } \\
\text { terados nos governos posteriores por contemplar sem profundidade algu- } \\
\text { mas especificidades (Educação indígena, Educação de Jovens e Adultos, } \\
\text { Relações Étnico-raciais, dentre outros) }\end{array}$ \\
\hline 1996 & $\begin{array}{l}\text { Criação do Grupo de Trabalho Intermi- } \\
\text { nisterial para a Valorização da População } \\
\text { Negra }\end{array}$ & $\begin{array}{l}\text { Criação de medidas especiais e temporárias para eliminação de desigual- } \\
\text { dades históricas (raciais, étnicos, religiosos, de gênero, dentre outros). }\end{array}$ \\
\hline 1997 & \begin{tabular}{|l|} 
Parâmetros Curriculares Nacionais \\
(Séries Iniciais do Ensino Fundamental)
\end{tabular} & $\begin{array}{l}\text { Pluralidade cultural, orientação sexual. Mais aproximado a um planeja- } \\
\text { mento pedagógico para e não com... }\end{array}$ \\
\hline 1998 & Parecer CEB No 04/98 & $\begin{array}{l}\text { Diretrizes Curriculares Nacionais para o Ensino Fundamental: meta o ideal } \\
\text { de uma crescente igualdade de direitos entre os cidadãos, baseado nos } \\
\text { princípios democráticos. }\end{array}$ \\
\hline 1998 & $\begin{array}{l}\text { Parâmetros Curriculares Nacionais } \\
\text { (Séries Finais do Ensino Fundamental) }\end{array}$ & $\begin{array}{l}\text { Temais transversais (Pluralidade cultural, orientação sexual, saúde, meio } \\
\text { ambiente): formação para a cidadania em } 4 \text { eixos: Dignidade da pessoa } \\
\text { humana; Igualdade de direitos; Participação e Co-responsabilidade pela } \\
\text { vida social. }\end{array}$ \\
\hline 1998 & Resolução CEB nº 3, de 26 de junho & $\begin{array}{l}\text { Diretrizes Curriculares Nacionais para o Ensino Médio - Art. } 3^{\circ} \text {, Inciso II: "a } \\
\text { Política da Igualdade, tendo como ponto de partida o reconhecimento dos } \\
\text { direitos humanos e dos deveres e direitos da cidadania..." }\end{array}$ \\
\hline 2000 & $\begin{array}{l}\text { Parâmetros Curriculares Nacionais (En- } \\
\text { sino Médio) }\end{array}$ & $\begin{array}{l}\text { "[...] a política da igualdade deve ser praticada na garantia de igualdade } \\
\text { de oportunidades e de diversidade de tratamentos dos alunos e dos pro- } \\
\text { fessores para aprender e aprender a ensinar os conteúdos curriculares". }\end{array}$ \\
\hline $2001-$ & Lei n 10172, de 9 de janeiro de 2001. & $\begin{array}{l}\text { Plano Nacional de Educação (2001-2010) - Ênfase na "...construção de } \\
\text { uma escola inclusiva, que garanta o atendimento à diversidade humana." }\end{array}$ \\
\hline
\end{tabular}

${ }^{5}$ Como orientação definia as políticas de "ações afirmativas" como "[...] medidas especiais e temporárias, tomadas pelo 


\section{A DIVERSIDADE NAS POLÍTICAS EDUCACIONAIS NO BRASIL | Paulo Gomes Lima}

Após compromisso assumido pelo Estado brasileiro na III Conferência Mundial de Combate ao Racismo, Discriminação Racial, Discriminação Racial, Xenofobia e Intolerância Correlata em Durban, África do Sul, realizada no 31 de agosto a 8 de setembro de 2001, portanto, já quase no final do segundo governo de Fernando Henrique Cardoso, caberia ao novo presidente do Brasil, criar meios e políticas para a consolidação dessa perspectiva no conjunto de suas políticas de diversidade.

Ao ser eleito em 2002 e assumir o governo em 2003, o governo de Luís Inácio Lula da Silva, tinha como parte de seu plano de governo atender parte das demandas históricas de movimentos sociais e que se embora de forma fragmentada ocorriam, seria necessário uma maior intencionalidade e priorização da agenda e efetividade de ações. Assim, nesse primeiro ano de governo, o então recém-eleito presidente da república cria duas importantes secretarias, cujo papel seria atender e ampliar o atendimento às demandas das mulheres brasileiras e do movimento negro, respectivamente: Secretaria Especial de Políticas para as Mulheres (SPM) e a Secretaria Especial de Políticas de Promoção da Igualdade Racial (SEPPIR). Ainda no ano de 2003, por meio da Lei n. 10.639, de 9 de janeiro a LDBEN 9394/1996 fora alterada, incluindo no currículo oficial da Rede de Ensino a obrigatoriedade da temática "História e Cultura Afro-Brasileira" e na mesma lei, por meio do Art. 79-B no calendário escolar fora incluído o dia 20 de novembro como 'Dia Nacional da Consciência Negra'.

No ano de 2004, na gestão do ministro da Educação Tarso Genro, foi criada a SECAD (Secretaria de Educação Continuada, Alfabetização e Diversidade), como um órgão que passaria a compor a estrutura administrativa do Ministério da Educação, cuja principal finalidade seria a de, junto com outras três secretarias (SEB-Secretaria de Educação Básica, Setec-Secretaria de Educação Tecnológica e Secretaria do Ensino Superior - SESU) articular, criar e ampliar políticas de acesso à educação para todos, a partir das demandas centradas na diversidade e especificidades, a saber: gênero, idade, raça e etnia, etc. Das três secretarias, segundo Moehlecke (2009), foi a SECAD que melhor explicitou as suas ações, compreensões e encaminhamentos sobre a diversidade, visto ampliar posicionamento crítico sobre as oportunizações sociais para e além das políticas das diferenças.

Uma outra ação do governo Lula, por meio do Decreto $n^{\circ} 6.094$, de 24 de abril de 2007, foi o Plano de Desenvolvimento da Educação (PDE), que dispunha sobre a implementação do Plano de Metas Compromisso Todos pela Educação, pela União Federal, em regime de colaboração com Municípios, Distrito Federal e Estados, e a participação das famílias e da comunidade, mediante programas e ações de assistência técnica e financeira, visando a mobilização social pela melhoria da qualidade da educação básica. Trouxe como um de seus pressupostos a discussão sobre a inclusão e preservação do direito às diferenças, "[...] realizando a diversidade na igualdade como fundamento primeiro do ato educativo..." (BRASIL, 2007). Tanto por força da nova forma de organização da Educação Básica, as grandes temáticas e pressupostos relacionados à inclusão e diversidade em maior ou menor grau passaram a integrar a referência educacional brasileira.

Destaca-se que por meio do Decreto presidencial n. 7.480 de Dilma Rousseff, de 16 de maio de 2011, que passou a vigorar a partir de 23 de maio de 2011 e com a extinção da Secretaria de Educação Especial (SEESP), "a inclusão" seria acrescentada à SECAD, passando a ser denominada

Estado (...) com o objetivo de eliminar desigualdades historicamente acumuladas, garantindo a igualdade de oportunidade e tratamento, bem como de compensar perdas provocadas pela discriminação e marginalização, por motivos raciais, étnicos, religiosos, de gênero e outros" (BRASIL,1996, p.10). Vale destacar que embora o GT partisse de uma demanda inicial para a valorização da população negra, não havia como não considerar outras demandas nas discussões do mesmo, visto o grau de marginalização histórico, cujo simples reconhecimento da existência e condições geradoras, deveriam ser objetos de encaminhamento. 
SECADI. Esse primeiro diploma legal foi revogado por meio do Decreto n.7.690, de 2 de março de 2012, com pouca alteração estrutural, mantendo se a SECADI como nova sigla da Secretaria de Educação Continuada, Alfabetização, Diversidade e Inclusão.

Conforme Moehlecke (2009, p.473-475), algumas ações, programas e projetos desenvolvidos ainda que começados no governo de Fernando Henrique Cardoso foram destacados e desenvolvidos pelo Ministério da Educação:

\section{QUADRO 1 - Programas/Projetos/Ações do Ministério da Educação que trabalham com a diversidade}

\begin{tabular}{|c|c|c|c|}
\hline $\begin{array}{l}\text { Responsável } \\
\text { Institucional* }\end{array}$ & Programa/ação & Início & Atividade \\
\hline SEB & $\begin{array}{l}\text { Programa Nacional de } \\
\text { Avaliação do Livro Didático }\end{array}$ & $1998^{* *}$ & $\begin{array}{l}\text { Observação da possível veiculação de estereótipos étni- } \\
\text { co-raciais e de gênero nos critérios de avaliação dos livros } \\
\text { didáticos. }\end{array}$ \\
\hline SESU & $\begin{array}{l}\text { Programa de Financiamento } \\
\text { Estudantil Lei n.10.260/01 }\end{array}$ & 1999 & $\begin{array}{l}\text { Foram incluídos como critérios para o financiamento, em } \\
2004 \text {, além da renda, a cor/raça e a escola frequentada. }\end{array}$ \\
\hline SECAD & $\begin{array}{l}\text { Programa Diversidade } \\
\text { na Universidade } \\
\text { Lei n. } 10.558 / 02\end{array}$ & 2002 (set.) & $\begin{array}{l}\text { Projeto de Financiamento de Cursos pré-vestibulares para o } \\
\text { acesso de afrodescendentes e indígenas ao ensino superior } \\
\text { (2003 até o momento). Em 2004, realizou fóruns estadu- } \\
\text { ais para fortalecer a temática da diversidade étnico-racial; } \\
\text { em } 2006 \text {, criou o Projeto de Tutoria para jovens negros no } \\
\text { ensino médio e superior e desenvolveu formação de profes- } \\
\text { sores da educação básica na Lei n. } 10.639 / 2003 \text {. }\end{array}$ \\
\hline SEESP & $\begin{array}{l}\text { Programa Educação } \\
\text { Inclusiva: Direito à } \\
\text { Diversidade }\end{array}$ & 2003 & $\begin{array}{l}\text { Apoio à disseminação da educação inclusiva nos municípios } \\
\text { e disponibilização de equipamentos e material pedagógico. }\end{array}$ \\
\hline SEESP/CAPES & $\begin{array}{l}\text { Programa de Apoio à } \\
\text { Educação Especial }\end{array}$ & 2003 & $\begin{array}{l}\text { Apoio e incentivo à pesquisa, em nível stricto sensu, para } \\
\text { profissionais que atuam na educação inclusiva. }\end{array}$ \\
\hline $\begin{array}{l}\text { Parceria } \\
\text { MEC/SEPPIR }\end{array}$ & Programa Brasil Quilombola & 2003 & $\begin{array}{l}\text { Ações de formação de professores para áreas de rema- } \\
\text { nescentes de quilombos, fóruns estaduais, melhoria da rede } \\
\text { escolar e a produção de material didático. }\end{array}$ \\
\hline $\begin{array}{c}\text { Parceria } \\
\text { MEC/SEDH }\end{array}$ & $\begin{array}{l}\text { Elaboração do Plano } \\
\text { Nacional de Educação } \\
\text { em Direitos Humanos }\end{array}$ & 2003 e 2006 & $\begin{array}{l}\text { Sistematização de um conjunto de programas/ ações de } \\
\text { educação em direitos humanos que tem como um de seus } \\
\text { princípios o respeito à diversidade. }\end{array}$ \\
\hline SESU & $\begin{array}{c}\text { Elaboração do Projeto de Lei } \\
\text { n.7.200/06: Reforma da } \\
\text { Educação Superior }\end{array}$ & 2004 & $\begin{array}{l}\text { Propõe a regulamentação do ensino superior brasileiro e } \\
\text { define políticas de ações afirmativas para alunos negros, } \\
\text { indígenas e de baixa renda. }\end{array}$ \\
\hline $\begin{array}{c}\text { Parceria } \\
\text { MEC/ SEPPIR }\end{array}$ & $\begin{array}{l}\text { Comitê Interministerial } \\
\text { de Políticas de Ações } \\
\text { Afirmativas }\end{array}$ & 2004 / 2005 & $\begin{array}{l}\text { Elaboração e encaminhamento ao Congresso do } \mathrm{PL} \text { no. } \\
\text { 3.627/04: Destina percentual de vagas nas Ifes para estu- } \\
\text { dantes de escolas públicas, negros e indígenas. }\end{array}$ \\
\hline SESU & $\begin{array}{l}\text { Projeto de extensão } \\
\text { universitária para a inclusão }\end{array}$ & 2004 & $\begin{array}{l}\text { Abrange programas de extensão universitária com ênfase } \\
\text { na inclusão de pessoas com deficiência, população indíge- } \\
\text { na e quilombola. }\end{array}$ \\
\hline SESU & $\begin{array}{l}\text { Monitoramento ações } \\
\text { afirmativas nas IES }\end{array}$ & 2004 & $\begin{array}{l}\text { Constituição de banco de dados sobre as Ifes e lees públi- } \\
\text { cas que adotam ações afirmativas }\end{array}$ \\
\hline SEESP & $\begin{array}{l}\text { Projeto Educar na } \\
\text { Diversidade }\end{array}$ & 2004 & $\begin{array}{l}\text { Formação de professores do ensino regular para desenvol- } \\
\text { ver práticas de ensino inclusivas. }\end{array}$ \\
\hline SECAD & $\begin{array}{l}\text { Programa Identidade Étnica } \\
\text { e Cultural Cultural dos Povos } \\
\text { Indígenas }\end{array}$ & 2004 & $\begin{array}{l}\text { Financiamento projetos de educação indígena, material } \\
\text { pedagógico e formação professores. }\end{array}$ \\
\hline SECAD & $\begin{array}{l}\text { Programa Diversidade } \\
\text { na Universidade }\end{array}$ & 2004 & $\begin{array}{l}\text { Sistematização de informações sobre demanda e oferta de ensino } \\
\text { médio em terras indígenas }\end{array}$ \\
\hline
\end{tabular}


A DIVERSIDADE NAS POLÍTICAS EDUCACIONAIS NO BRASIL | Paulo Gomes Lima

\begin{tabular}{|c|c|c|c|}
\hline $\begin{array}{c}\text { Parceria } \\
\text { SEB(MEC)/SEDH }\end{array}$ & $\begin{array}{l}\text { Programa Ética e } \\
\text { Cidadania }\end{array}$ & 2004 & $\begin{array}{l}\text { Criação de fóruns de ética e cidadania em escolas públicas, } \\
\text { abordando temas como inclusão social e discriminação. }\end{array}$ \\
\hline SESU & $\begin{array}{l}\text { Programa Universidade } \\
\text { para Todos Lei n. 11.096/05 }\end{array}$ & 2004 & $\begin{array}{l}\text { Destinação de bolsas de estudos a alunos de baixa renda, } \\
\text { com percentual de vagas para estudantes negros, indíge- } \\
\text { nas e deficientes. }\end{array}$ \\
\hline SECAD & $\begin{array}{l}\text { Projeto Conexões de } \\
\text { Saberes }\end{array}$ & 2004 & $\begin{array}{l}\text { Estímulo à articulação universidade e comunidades popu- } \\
\text { lares, com financiamento bolsas para estudantes. Conta } \\
\text { com } 32 \text { lfes. }\end{array}$ \\
\hline $\begin{array}{l}\text { Parceria } \\
\text { MEC/SEPPIR/ } \\
\text { SEDH/MS }\end{array}$ & $\begin{array}{l}\text { Programa de Integração } \\
\text { de Ações Afirmativas } \\
\text { para Negros }\end{array}$ & 2004 & $\begin{array}{l}\text { Concessão de } 500 \text { bolsas para estudantes universitários } \\
\text { pesquisarem temas relacionados à DST/Aids. }\end{array}$ \\
\hline SESU /SEESP & Programa Incluir & 2005 & $\begin{array}{l}\text { Busca garantir o acesso e a permanência em igualdade de } \\
\text { oportunidades para estudantes com necessidades espe- } \\
\text { ciais no ensino superior. }\end{array}$ \\
\hline SESU /SECAD & $\begin{array}{l}\text { Programa de Formação } \\
\text { Superior e Licenciaturas } \\
\text { Indígenas }\end{array}$ & 2005 & $\begin{array}{l}\text { Apoio a projetos de IES públicas, juntamente com as comu- } \\
\text { nidades indígenas, para a formação superior de docentes } \\
\text { indígenas e a permanência de estudantes na graduação. }\end{array}$ \\
\hline SESU /SECAD & $\begin{array}{l}\text { Programa de Ações } \\
\text { Afirmativas para a } \\
\text { População Negra }\end{array}$ & 2005 & $\begin{array}{l}\text { Apoio a projetos dos Núcleos de Estudos Afro-brasileiros } \\
\text { para produzir conhecimento sobre a temática étnico-racial e } \\
\text { ampliar o acesso dos negros ao ensino superior. }\end{array}$ \\
\hline SECAD & $\begin{array}{l}\text { Programa Educação } \\
\text { para a Diversidade e } \\
\text { Cidadania }\end{array}$ & 2005 & $\begin{array}{l}\text { Apoio à qualificação de profissionais da Educação com } \\
\text { relação aos temas de orientação sexual e de identidade de } \\
\text { gênero. }\end{array}$ \\
\hline SECAD & $\begin{array}{l}\text { Projeto Educando para } \\
\text { a Igualdade } \\
\text { Gênero, Raça e } \\
\text { Orientação Sexual }\end{array}$ & $2005-2006$ & $\begin{array}{l}\text { Formação de Professores: Gênero, Orientação Sexual e Di- } \\
\text { versidade Étnico-Racial em } 5 \text { estados. }\end{array}$ \\
\hline SESU & $\begin{array}{l}\text { Programa Milton Santos } \\
\text { de Acesso ao Ensino } \\
\text { Superior }\end{array}$ & 2005 & $\begin{array}{l}\text { Destinação de bolsas de estudo para estudantes de países } \\
\text { em desenvolvidos, especialmente africanos. }\end{array}$ \\
\hline
\end{tabular}

* No âmbito do MEC funcionam as seguintes Secretarias envolvidas com políticas de diversidade: Secretaria de Educação Básica - SEB; Secretaria de Educação Superior - Sesu; Secretaria de Educação Continuada, Alfabetização e Diversidade - Secad; Secretaria de Educação Especial - Seesp. Em relação às parcerias com outros Ministérios, temos o Ministério da Saúde - MS - , a Secretaria de Especial de Direitos Humanos - Sedh - e a Secretaria Especial de Políticas para a Promoção da Igualdade Racial - Seppir.

** O hífen indica que o programa continuava em funcionamento ao final de 2006.

FONTE: Moehlecke (2009, p.473-475).

Os fóruns de discussão sobre as temáticas e políticas de diversidade, com maior vulto para as Conferências Nacionais de Educação $(2010,2014)$ trouxeram importantes contribuições em nível conceitual e de planejamento político. A CONAE/2010, realizada de 28 de março a $1^{\circ}$ de abril em Brasília-DF, "Construindo o Sistema Nacional Articulado de Educação: O Plano Nacional de Educação, Diretrizes e Estratégias de Ação", trouxe no Eixo Temático VI - "Justiça Social, Educação e Trabalho: Inclusão, Diversidade e Igualdade", debates sobre pelo menos doze pontos: 1. Política de Ações Afirmativas para Estudantes: Promovendo a Igualdade, 2. Estratégias de Superação da Violência no Ambiente Educacional; 3. Educação e Mundo do Trabalho; 4. Educação e Relações Étnico-raciais e Multiculturais; 5. Educação Ambiental e Contextualização Curricular; 6. Diversidade Regional e Contextualização Curricular; 7. Educação do Campo; 8. Educação Escolar Indígena e Territorialidade; 9. Direito à Educação para Adolescentes em Medidas Socioeducativas e para Pessoas Privadas de Liberdade; 10. Educação e Diversidade sexual; 11. Educação de Pessoas com Deficiências, Transtornos Globais de Desenvolvimento e Altas Habilidades/Superdotação; 12. A Pós-Graduação, a Produção e a Socialização do Conhecimento Científico. Observa-se 


\title{
A DIVERSIDADE NAS POLÍTICAS EDUCACIONAIS NO BRASIL | Paulo Gomes Lima
}

embora uma grande quantidade de pontos tenha sido privilegiada no debate, o conceito sobre diversidade ainda não estava acordado, o que deveria ser contemplado na CONAE posterior.

Por sua vez, a CONAE/2014 realizada em Brasília-DF, no período de 19 a 23 de novembro de 2014, com o tema "O PNE na Articulação do Sistema Nacional de Educação: Participação Popular, Cooperação Federativa e Regime de Colaboração”, no Eixo II - Educação e Diversidade: Justiça Social, Inclusão e Direitos Humanos, amplia a discussão e traz um conceito que passa a ser amplamente divulgado e aceito para efeitos de políticas educacionais, ou seja, a diversidade como "[...] dimensão humana, deve ser entendida como a construção histórica, social, cultural e política das diferenças que se expressa nas complexas relações sociais e de poder." Em relação às políticas educacionais o documento referência (CONAE, 2014, p.29) defende a:

\footnotetext{
[...] garantia do direito à diversidade na política educacional e a efetivação da justiça social, da inclusão e dos direitos humanos implicam a superação de toda e qualquer prática de violência e discriminação, proselitismo e intolerância religiosa. Para tal, a educação nos seus níveis, etapas e modalidades deverá se pautar pelo princípio da laicidade, entendendo-o como um dos eixos estruturantes da educação pública e democrática. a laicidade é efetivada não somente por meio dos projetos político-pedagógicos e dos planos de desenvolvimento institucionais, mas, também, pelo exercício cotidiano da gestão e pela prática pedagógica.
}

O segundo PNE (2014-2024), gerado das discussões das CONAES $(2010,2014)$ e demais fóruns, por meio de sua aprovação (Lei n 13.005, de 25 de junho de 2014), trouxe dentre outras como diretriz em seu artigo $2^{\circ}$, a necessidade de "III - superação das desigualdades educacionais, com ênfase na promoção da cidadania e na erradicação de todas as formas de discriminação."; outro ponto no mesmo artigo: "X - promoção dos princípios do respeito aos direitos humanos, à diversidade e à sustentabilidade socioambiental." Dentre suas 20 metas, podemos destacar um grupo de metas que trata especificamente da redução das desigualdades e valorização da diversidade, por meio da inclusão e centralidade no atendimento às suas especificidades nas políticas públicas de educação:

\begin{abstract}
Meta 4: universalizar, para a população de 4 (quatro) a 17 (dezessete) anos com deficiência, transtornos globais do desenvolvimento e altas habilidades ou superdotação, o acesso à educação básica e ao atendimento educacional especializado, preferencialmente na rede regular de ensino, com a garantia de sistema educacional inclusivo, de salas de recursos multifuncionais, classes, escolas ou serviços especializados, públicos ou conveniados. Meta 8: elevar a escolaridade média da população de 18 (dezoito) a 29 (vinte e nove) anos, de modo a alcançar, no mínimo, 12 (doze) anos de estudo no último ano de vigência deste plano, para as populações do campo, da região de menor escolaridade no País e dos $25 \%$ (vinte e cinco por cento) mais pobres, e igualar a escolaridade média entre negros e não negros declarados à Fundação Instituto Brasileiro de Geografia e Estatística - IBGE.
\end{abstract}

Essas metas, como parte das ações do Brasil para fazer valer o direito das diversidades tem como finalidade ampliar a dimensão do direito que previsto, não era e não é objeto de alcance de todos os grupos previstos, mas ainda sabemos que embora alargado hoje, ainda é necessários esforços mais concretos que efetivem medidas de não-exclusão social.

As oportunizações sociais e o respeito à 'diversidade', em relação à inclusão social à educação em suas distintas manifestações contemplaram, dentre outras, a lei 12.711/2012 que dispunha sobre o ingresso nas universidades federais e nas instituições federais de ensino técnico de nível médio e previa outras providências. É óbvio que o gargalo histórico de inclusão social não seria atendido de forma plena, pois a discriminação positiva, por meio das políticas de ações afirmativas, não previa a "universidade para todos", mas uma forma de abertura percentual da mesma, dada 


\section{A DIVERSIDADE NAS POLÍTICAS EDUCACIONAIS NO BRASIL | Paulo Gomes Lima}

a necessidade de ampliar a discussão e se estruturar outra lógica para o acesso e democratização da educação superior, objeto que ainda não se caracteriza como ponto resolvido no Brasil.

Portanto, a partir da Constituição Federal de 1998 com a previsão e garantia implícita dos padrões de proteção dos direitos fundamentais, da LDBEN 9394/96 e mais recentemente com legislações específicas, como destacado no percurso desse trabalho, integram a agenda das políticas educacionais voltadas para diversidade, ora como temas, como modalidade educacional e como parte diversificada do currículo como propõe a Base Nacional Curricular Comum (BRASIL, 2016). Dentre os temas estão:

- Educação de jovens e adultos

- Educação do campo

- Relações étnico-raciais

- Educação escolar indígena

- Educação escolar quilombola

- Educação ambiental
- Educação especial

- Gênero e sexualidade

- Educação de jovens cumprindo medidas socioeducativas

- Educação em sistemas prisionais

Como uma dimensão em direção à equidade, as modalidades da educação no Brasil, se caracterizam por sua especificidade no interior do sistema educacional, isto é, dar conta de atendimento às demandas específicas, garantindo-se que as injustiças sociais (a marginalização, dentre outros), sejam combatidas com vistas à não inferiozar pessoas ou grupos sociais e ainda garantir-lhes o direito cidadão à educação. Como exemplo, integram as modalidades de educação no Brasil:

- Educação especial na perspectiva inclusiva

- Educação escolar quilombola

- Educação do campo

- Educação escolar indígena

- Educação de jovens e adultos

Certamente a parte diversificada do currículo no cotidiano escolar, dentre outros pontos, deve primar por abrir e adensar espaços de discussão sobre as recorrências e fortalecimento das comunidades que, em seu conjunto, deve se tornar objeto de sala de aula, porque legitimada pelos valores convencionados, considerando a qualidade de ensino como ponto comum e a identidade, especificidades e demandas com vistas ao desvelamento do homem e do mundo num contexto de enfrentamento das perversidades sociais.

Quando se analisa todo o contexto de formação do povo brasileiro e o itinerário entre a apropriação e expropriação cultural e econômica, as demandas pelo direito de cidadania e respeito à diversidade e diferenças, há que se trazer pensar sobre as causas dos obstáculos à sua consecução de maneira universal e, portanto, mais humana e democrática. O reconhecimento dos direitos é parte de um todo, mas não suficiente e muitas vezes, no contexto de socialização do direito, a filtragem por meio de percentuais de cidadania, nos torna cidadãos como todo cidadão? Mas, isso não acontece no contexto da estrutura capitalista, como suficiência e dimensão da democracia defendida na contemporaneidade, no Brasil e em outros países? Se as políticas educacionais como ações plenas e suficientes, outorgadas por um "bom governante", não estamos reduzindo o próprio núcleo do que Paulo Freire chamava de emancipação e construção de uma consciência coletiva?

A partir da consciência coletiva da cidadania como valor ético-político entendemos o direito e a justiça social como elementos que se integram e primam pela superação das parcialidades no 


\section{A DIVERSIDADE NAS POLÍTICAS EDUCACIONAIS NO BRASIL | Paulo Gomes Lima}

seio educacional, cultural, econômico, etc. É claro que seria ingenuidade não considerarmos a sociedade capitalista em que vivemos, uma vez que no marco de suas contenções se buscam as suas problematizações e encaminhamentos. É sabido que embora as políticas focais, com forte ênfase na discriminação positiva, tenham propiciado a "inclusão" de alguns, outros fortemente em percentuais elevados não compartilharam a mesma experiência, portanto, não se toma a democratização do acesso mediante parcialidades como questão resolvida, mas como um passo que podem abrir outras fronteiras de ampliação no âmbito da desigualdade de condições humanas e sociais, o que exigirá uma sociedade não-excludente, que deverá pensar a sua tipologia e a dos cidadãos em sua universalidade, diversidade e diferença.

Como afirma Lima (2009) a partir da consciência coletiva surgem e são encaminhados questionamentos acerca de uma outra sociedade que entende justiça social não como consentimento ou espaço de inclusão, mas como espaço da não-exclusão em todo e qualquer grau, do não antagonismo na redistribuição de renda, do direito à terra e à categoria mais importante, a humanização em seu sentido mais amplo.

\section{4 | DIVERSIDADE NAS POLÍTICAS EDUCACIONAIS: ALGUMAS PONTUAÇÕES E RECOR- RÊNCIAS}

Embora o respeito, reconhecimento e efetivação do direito à diversidade como dimensão humana e, portanto, construção histórica, social, cultural e política à luz das políticas educacionais devam ser pauta da prática democrática, inclusive na busca da igualdade social e na denúncia e superação das desigualdades existentes; para a realidade brasileira, existem muitas lacunas que precisam ser problematizadas. Um recorte das mesmas se pode verificar na diluição cada vez mais acentuada de previsões sobre os direitos humanos e sociais nas legislações e distanciamentos em sua materialização, com alcance reduzido e/ou inviabilizado pela não observância das metas e estratégias sociais do combate à violência, à oportunização social, proselitismo religioso (e também o político partidário) e discriminações que afetam a dignidade humana, dentre outros.

Do censo realizado pelo INEP (2016) tem-se um total de 48.796 .512 matrículas na Educação Básica e modalidades, certamente há vários números que podem nos fazer pensar o descompasso das solicitações reais para fazer o enfrentamento e o quadro atual, por exemplo, a taxa de analfabetismo registrada pelo IBGE (2010) no Censo era de aproximadamente $9 \%$ de pessoas, o que equivaleria dizer que 18 milhões de brasileiros precisariam ser atendidos nessa demanda. Entretanto, o Censo Escolar (INEP, 2016), aponta o número de 3.491.869 matrículas efetivadas entre EJA regular e profissionalizante. A mesma relação se aplica quando se verifica a necessidade de atendimento no campo de Educação Especial, Educação do Campo, Educação Indígena e Educação Escolar Quilombola. E quando pensamos no respeito em respeito à construção de uma sociedade que oportuniza meios e condições para que todas as pessoas em sua dignidade, inteireza legal, justiça social tenham garantidas suas prerrogativas, observamos certamente que já saímos do ponto de inércia na elaboração de políticas públicas, especialmente àquelas direcionadas para a educação, no entanto, a luta primeiro por sua efetivação e depois por sua ampliação e esperançosamente democratização em sentido pleno, ainda é uma batalha que não está resolvida. Se estará no arranjo social atual não se tem resposta, visto o conjunto de condicionantes políticos, ideológicos e econômicos que transversaliza a tipologia do sujeito a ser formado para uma tipologia social.

Silva (2002, p. 175) destaca que as políticas educacionais no Brasil, de forma geral caracterizam-se pelo consentimento naturalizado de uma dinâmica que atenta para: a) supressão da concepção de direito; b) explicitação de sua natureza contencionista-reformista, compensatória e 


\section{A DIVERSIDADE NAS POLÍTICAS EDUCACIONAIS NO BRASIL | Paulo Gomes Lima}

discricionária; c) valorização de resultados estatísticos (ênfase no retorno dos investimentos capitalistas efetuados); d) incorporação de estratégias que reforçam o deslocamento das decisões do âmbito público para o privado; e) hierarquização das instituições escolares e acadêmicas; f) estimulação do setor privado para decisões, gerenciamento e execução, g) indução para que as instituições educativas assemelhem-se à lógica empresarial, h) priorização dos critérios econômicos e redução da educação à formação para o trabalho.

A questão central é: se dentro do espaço de conformação da realidade capitalista no Brasil quando da discussão e encaminhamento da diversidade nas políticas educacionais, chega-se e defende-se unilateralmente que os parâmetros legais e institucionalizados respondem o cerne das demandas dos grupos solicitantes, não se estaria reduzindo a própria lógica da justiça social do para todos, ainda que dentro do próprio grupo? E quando ao todos universal? Essa questão provoca a lembrança do recente filme americano "Selma", cujo protagonista, Martin Luther King, se posiciona radicalmente contra quanto ao fracionamento do direito civil do negro, o voto foi um exemplo, mas em sua reivindicação a lógica do direito civil, político e social pretendia o reconhecimento e integração do povo norte-americano negro à cidadania e bens produzidos, visto que o segregacionismo que já existia, acentuava o lugar de um e outro grupo, delimitando a desigualdade social, econômica, de raça, dentre outros.

Assim, no caso brasileiro, se um passo na direção da reflexão e mobilização de vários grupos foram dados, como expresso nesse trabalho, é necessário ainda que a jornada não se dê por concluída, uma vez que:

Uma ordem jurídica não pode limitar-se apenas a garantir que toda pessoa seja reconhecida em seus direitos por todas as demais pessoas; o reconhecimento recíproco dos direitos de cada um por todos os outros deve apoiar-se, além disso, em leis legítimas que garantam a cada um liberdades iguais, de modo que "a liberdade do arbítrio de cada um possa manter-se junto com a liberdade de todos". (HABERMAS, 2003, p.52)

Nesse caso, a justiça social em seu sentido indistinto é deslocada para o âmbito da retórica, prevalecendo um desvio conceitual de equidade e, portanto, do alcance do direito a ter direitos. É possível uma dimensão de equidade em seu sentido mais concreto e democrático, forjada em conformidade com as desigualdades sociais e com a divisão internacional do trabalho, das oportunizações sociais e do direito? Se isso não é possível, as aberturas por meio dos processos de democratização podem nos fornecer pistas e encaminhamentos para outras labutas e consequente reversão da perversidade social institucionalizada pela lógica do capital (LIMA, 2009).

\section{5| CONSIDERAÇÕES FINAIS}

Se a abertura do espaço de discussão, via políticas públicas para a diversidade foi objeto de luta e consecução ao longo de décadas no mundo e no Brasil, cabe não somente o enfrentamento de suas demandas, mas a ampliação para o enfoque emancipatório do que se entende por justiça social na educação brasileira. Quando os movimentos sociais, os representantes da diversidade em todas as suas manifestações e o cidadão (objeto de preocupação da mesma) conformam-se com arranjos pontuados de seus direitos em detrimento de uma parcela maior que totaliza 0 universo de excluídos, corre-se o risco de um entendimento e redução do conceito e vivência de justiça social que nesse sentido pode ser descaracterizada em sua profundidade, pautando-se como uma justiça formal fragmentada, isto é, define-se legalmente os parâmetros de justiça, entretanto, a totalidade de sua consecução é controlada de forma restritiva, porque classifica o seu 


\section{A DIVERSIDADE NAS POLÍTICAS EDUCACIONAIS NO BRASIL | Paulo Gomes Lima}

alcance em critérios descompassados, como a histórica meritocracia, dado que os mesmos instrumentos históricos de exclusão estão presentes também na contenção do acesso ao bem público, assim como acontece há muito tempo.

Ao legislador, ouvida a sociedade, cabe não somente ter como ponto de concórdia um conceito, o seu reconhecimento e atendimento no texto legal; é necessário previsão e articulação junto com o executivo para que o direito de todos seja preservado, ampliado e repensado. Assim, são colocados na agenda nacional as necessidades de oportunizações sociais na educação em nível de acesso, permanência e sucesso como espaço para todos e paralelamente o direito à diferença como efetivação e prerrogativa cidadã. Nesse sentido, a inclusão social é um arranjo que também precisa ser repensado, visto que o seu projeto no arranjo do capital não se remete ao contexto de "nenhum a menos", mas o de "um a mais por concessão do sistema; assim o quadro de expropriação ao direito não se altera, toma outro formato. A esse respeito diz Mészaros (2006, p.295):

A defesa insincera da 'igualdade de oportunidades' associada à 'imparcialidade' e à 'justiça' serve a um objetivo apologético, pois, ao se eliminar a verdadeira igualdade, do rol das aspirações legítimas, as hierarquias estruturais do sistema do capital são reforçadas e se tornam provedoras indispensáveis das vazias 'oportunidades' prometidas e, ao mesmo tempo, são aclamadas por sua 'imparcialidade'.

A transformação social que faz o contraponto a arranjos que imobilizam, excluem e reduzem as políticas educacionais frente às demandas concretas, requer a formação política do homem, objeto que não pode e não deve ser reduzida a formação política partidária, como defendem as diversas ideologias que preconizam o seu ideário particularizado de justiça social. Essa formação confere aos homens e mulheres um caráter emancipatório do exercício de sua cidadania que, por sua vez, tem na educação um dos instrumentos que possibilita a análise das construções históricas, políticas, sociais e culturais que devem ser contextualizadas, respeitadas e defendidas sempre, em especial, quando a negação ideologizante tenta fragmentar sua visão do mundo e do homem e reduzir a essência da democracia.

Como observado por Lima (2009) a democracia, ainda que na forma da lei, deve conduzir e ser conduzida pela justiça, não somente em seu sentido abstrato, embora se saiba de seus condicionantes e eixos delimitadores, mas paralelamente e, sobretudo como objeto de humanização e ação transformadora do homem, de sua autoprodução e de seu itinerário histórico. Para não encerrar o debate, mas ampliá-lo, entendemos que, se no seio do arranjo estrutural do capital, há a consecução de espaços e discussões, ainda que por concessão, como acontece em distintos arranjos governamentais, sobretudo no Brasil, a luta é pelo despertamento de consciência e busca, pelos meios legais disponíveis, para se fazer valer a justiça social para todos de fato, assim a "não-exclusão" deve ser objeto de inflexão, pois se torna radical quanto ao respeito e efetivação do direito à universalização e à diferença. Como afirma Lima (2009, p.2013), essa construção "[...] provocada pela educação, por meio da emancipação concreta da sociedade e do homem poderemos reunir a dimensão necessária de emancipação, libertação, justiça social, humanização e universalização das construções sociais". 


\section{Referências}

BRASIL. Decreto $n^{\circ}$ 6.094, de 24 de abril de 2007. Dispõe sobre a implementação do Plano de Metas Compromisso Todos pela Educação. Disponível em: http: // www.planalto.gov.br/ccivil_03/_Ato2007-2010/2007/Decreto/D6094.htm.Acesso em 03.11.2016.

BRASIL. Documento Referência da Conae 2010. Brasília: 2010.

BRASIL. Documento Referência da Conae 2014. Brasília: 2014.

BRASIL. Grupo de Trabalho Interministerial para a Valorização da População Negra. Brasília: Ministério da Justiça, 1996.

BRASIL. Ministério da Educação e Cultura. Base Nacional Curricular Comum. Documento Preliminar. Brasília, DF, 2016.

BRASIL. Ministério da Educação e Cultura. Planejando a Próxima Década Conhecendo as 20 Metas do Plano Nacional de Educação. Brasília, DF, 2014. Disponível em: http://pne.mec.gov.br/images/pdf/pne_conhecendo_20_metas.pdf. Acesso em 03.11.2016.

CLEMENTS, Phillip Edward; JONES, John. The diversity training handbook: a practical guide to understanding and changing attitudes. $2^{\mathrm{a}}$ edição. Londres: Kogan Page, 2002.

HABERMAS, Jürgen. Direito e democracia: entre facticidade e validade. Vol.I. Rio de Janeiro: Tempo Brasileiro, 2003.

HOFLING, Eloisa de Mattos. Estado e políticas (públicas) sociais. Cad. CEDES [online]. 2001, vol.21, n.55, pp.30-41.

INSTITUTO NACIONAL DE ESTUDOS E PESQUISAS ANISIO TEIXEIRA. Sinópse estatística da Educação Básica 2015. Brasilia: Inep, 2016. Disponível em: $<$ http//:portal.inep.gov.br/básica-censo-escolar-sinopse-sinopse>. Acesso em 10/11/2016.

LIMA, Paulo Gomes. Ações afirmativas como eixo de inclusão de classes sociais menos favorecidas à universidade brasileira: um terceiro olhar entre pontos e contrapontos. Relatório de Pesquisa (Pós-Doutorado em Educação). Campinas/SP: Universidade Estadual de Campinas, 2009.
LIMA, Paulo Gomes; MARRAN, Ana Lúcia. A avaliação de políticas educacionais por meio da abordagem teórico-analítica do ciclo de políticas. Práxis Educativa, Ponta Grossa, v. 8, n. 1, p. 41-62, jan/jun. 2013. Disponível em: http://www.revistas2.uepg.br/index.php/praxiseducativa. Acesso em 26.10.2016.

LONDON, Valerie. Formação de Formadores. In:_. Workshop Internacional sobre Equidade e Diversidade no Serviço Público: Gênero, Raça e Direitos Humanos, realizado em Brasília-DF de 19 a 21 de maio de 2009. Palestra.

MÉSZÁROS, Istvan. Para além do capital. São Paulo: Boitempo Editorial, 2006.

MOEHLECKE, Sabrina. As políticas de diversidade na educação no governo Lula. Cadernos de Pesquisa, São Paulo, v. 39, n. 137, maio/ago. 2009.

MONTAGNER, Paula et al. Diversidade e capacitação em escolas de governo: mesa-redonda de pesquisa-ação. Brasília: ENAP, 2010.

PALUMBO, Denis. J. Public policy in America: government in action. 2. ed. San Diego: Harcourt Brace \& Company, 1994. p. 8-29.

RODRIGUES, Tatiane Cosentino; ABRAMOWICZ, Anete. $\mathrm{O}$ debate contemporâneo sobre a diversidade e a diferença nas políticas e pesquisas em educação. Educ. Pesqui., São Paulo, v. 39, n. 1, p. 15-30, jan. /mar. 2013.

SANFELICE, José Luís. Inclusão educacional no Brasil: limites e possibilidades. Revista de Educação da Puc-Campinas, $\mathrm{N}^{\circ} 21$, p. 29-40, novembro de 2006.

SILVA, Graziella Moraes Dias da. Ações afirmativas no Brasil e na África do Sul. In:_. Tempo Social, revista de sociologia da USP, v. 18, n. 2, 2006.

SILVA, Maria Abádia da. Intervenção e consentimento: a política educacional do Banco Mundial. São Paulo: Autores Associados, 2002.

VIDOVICH, Lesley. A conceptual framework for analysis of education policy and practices. In:_. Australian Association for Research in Education Conference, 2001, Fremantle. Anais... Fremantle: AARE, 2001. 